\title{
MINOR SALIVARY GLAND MUCINOUS ADENOCARCINOMA OF BUCCAL MUCOSA - CASE REPORT AND REVIEW OF THE LITERATURE
}

\author{
Grażyna Wyszyńska-Pawelec ${ }^{1}$, Piotr Koryczan ${ }^{1}$, Jan ZapaŁa ${ }^{1}$, Michae Gontarz ${ }^{1}$, \\ Maciej Opach ${ }^{1}$, Piotr Kuśnierz ${ }^{1}$, Bogdan Kosowski ${ }^{2}$, Dariusz AdameK ${ }^{3}$
}

\author{
${ }^{1}$ Department of Cranio-Maxillofacial Surgery, Jagiellonian University Medical College, Krakow, Poland \\ ${ }^{2}$ Prosmed - Unit of Anatomopathology, Krakow, Poland \\ 3 Department of Pathology, Jagiellonian University Medical College, Krakow, Poland
}

\begin{abstract}
Mucinous adenocarcinoma (MAC) is commonly found in the gastrointestinal tract but head and neck localisations are very rare. This article presents the case of a 67-yearold patient suffering from a minor salivary gland MAC of the left buccal mucosa, who was treated in the Department of Cranio-Maxillofacial Surgery in Krakow due to multiple recurrences of the tumour. The results of immunohistochemical staining, the course of surgical treatment and follow-up, as well as a review of literature are also discussed.
\end{abstract}

Key words: mucinous adenocarcinoma, minor salivary glands, immunohistochemistry, radiography.

\section{Introduction}

Mucinous adenocarcinoma (MAC) is most frequently observed in the digestive organs. The most common localisation is the large intestine (colon), and it is estimated that MAC constitutes $10-20 \%$ of colorectal cancers, followed by the pancreas, ovary, lung, prostate, and breast [1]. The primary head and neck localisation of MAC is very rare and accounts for about $3 \%$ of salivary gland tumours. Salivary gland MACs are characterised by high aggressiveness due to a high rate of local recurrences and nodal metastasis [1-3].

The tumour is composed of large extracellular mucin pools and irregular-shaped neoplastic epithelial cells surrounded by numerous cystic cavities, separated by fibrous strands. The cancer cells have clear cytoplasm and small, round, darkly-stained nuclei. The tumour cells form nests embedded in the extracellular mucin pools [3-7]. According to some authors the histological features are so characteristic that differential diagnosis from other malignant salivary gland tumours is straightforward [5]. On the other hand, there are au- thors who regard MAC's recognition criteria as controversial and inconclusive $[3,6,8]$. According to the WHO, the microscopic image is dominated by small foci of cancer cells or even single cells surrounded by large areas of extracellular mucin separated by connective fibrous strands. In addition, at least half of the tumour cells should produce mucus [8]. Histologically, MAC may be confusingly similar to the mucinous eccrine carcinoma of the skin, mucinous carcinoma of the breast and colloid carcinoma of the bowel [7]. An important feature of MAC are mucus-producing cells which show positive staining for mucicarmine and Alcian blue. However, these cells are also characteristic for other salivary gland tumours; hence immunohistochemical (IHC) staining is helpful in differential diagnosis. Typical for MAC is a strongly positive reaction for cytokeratins (CK) AE1/AE3,7, intermediate or strong reaction for CK 8, 18, 19, positive reaction for epithelial membrane antigen (EMA), vimentin, carcinoembryonic antigen (CEA), and varied reaction with $\alpha$-SMA (smooth muscle actin), $\alpha$-amylase and calcitonin. Cytokreatins, vimentin, S-100 protein, and $\alpha$-SMA pos- 
itive staining is characteristic for most salivary gland tumours $[3,4,6]$. Some authors believe that the positive reaction for neuron specific enolase (NSE), calcitonin and somatostatin may be the evidence of neuroendocrine differentiation, but the exact significance of this expression is unknown [8]. Primary minor salivary gland MAC requires exclusion of metastatic nature of the tumour. An important feature of salivary gland MACs is a clear difference in the number of chromosomal aberrations in comparison with MAC of digestive organs [1].

\section{Case report}

A 67-year-old patient reported to the Outpatient Unit of the Department of Cranio-Maxillofacial Surgery due to a large tumour involving the left half of the face. The lesion had been observed by the patient for about 12 years, originally removed as an epidermal cyst of the left cheek in the regional hospital. Three years later a recurrent tumour in the postoperative scar was removed. The histological examination revealed gelatinous adenocarcinoma, most likely arising from a minor salivary gland of the oral mucosa; the lesion was excised without adequate margins. The patient was consulted in the Department of Oncology but due to the radioresistance of the tumour he was disqualified from

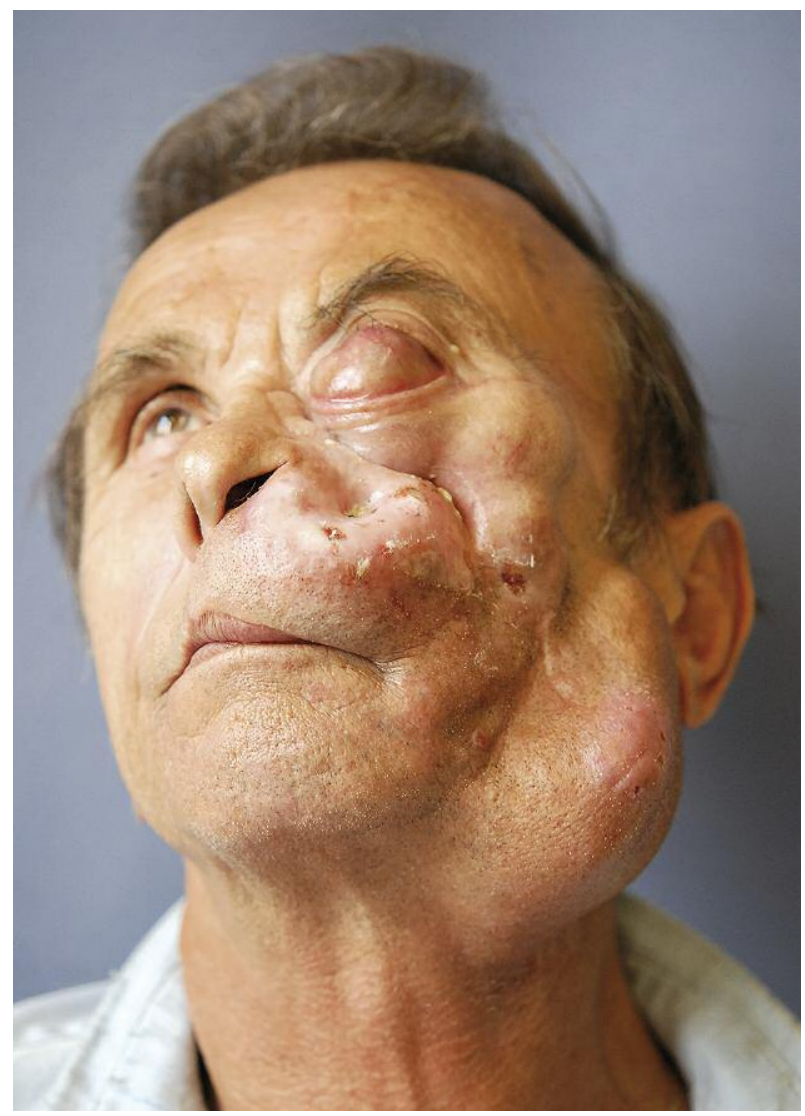

Fig. 1. The patient with minor salivary gland MAC of the buccal mucosa infiltrating the left half of the face adjuvant radiotherapy and was admitted to our department in order to extend the surgical resection. In 1997 the excision of the tumour of the left infraorbital area with resection of the underlying bone was performed; the defect was reconstructed by the frontal flap. The margins of resection were positive; thus an additional extended excision of the postoperative scar was carried out. This time there were no signs of the tumour in the histopathological examination. In 1999 the next excision of the local recurrence was carried out, and the histological examination indicated radical excision. In 2007 the patient reported again to our department with the suspicion of local recurrence in the left cheek but did not consent to the proposed surgery and avoided follow-up examination until 2012, when the patient reappeared, presenting an extensive tumour involving the whole left half of the face infiltrating the orbit, infraorbital area, left cheek as well as masseteric area and submandibular region on the left side (Fig. $1,2)$. The range of the tumour was confirmed in CT of the facial part of the skull (Fig. 3, 4). Diagnostic biopsy was performed. During collection of the diagnostic material, a jelly-like consistency of the tumour could be observed with an abundant outflow of mucus. The results of basic blood tests revealed no abnormalities. The ultrasound examination of the abdomen and

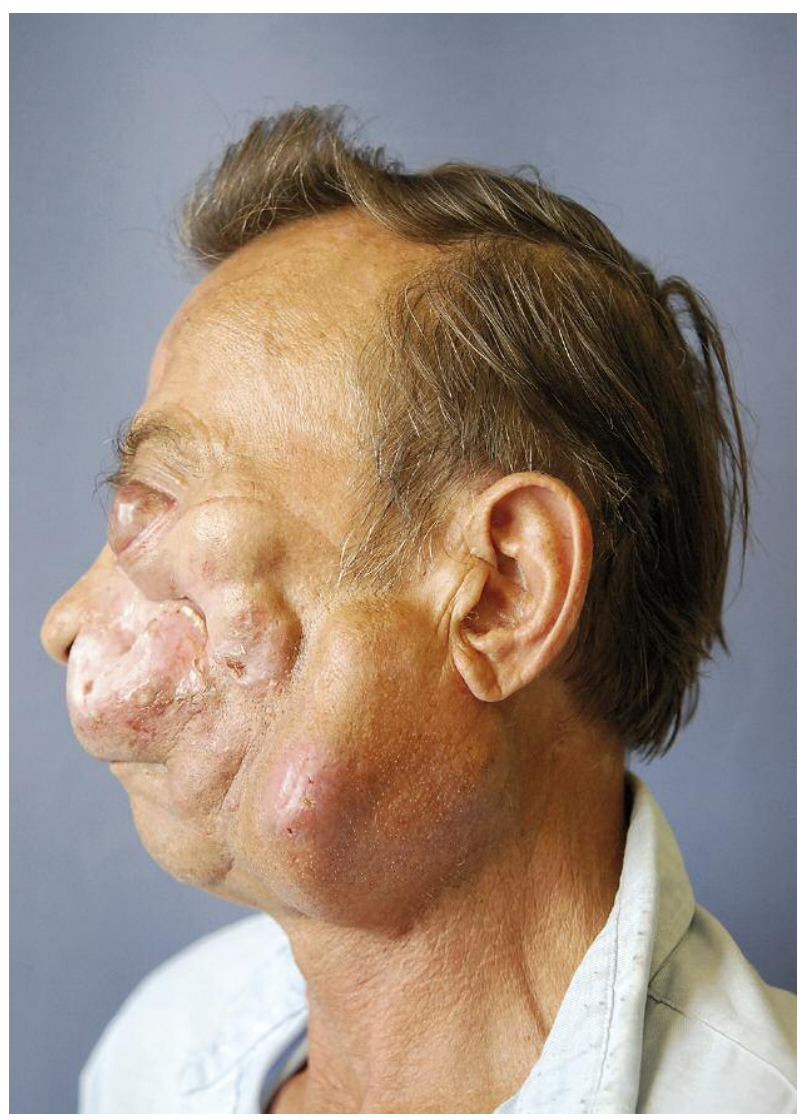

Fig. 2. The same patient - lateral view 


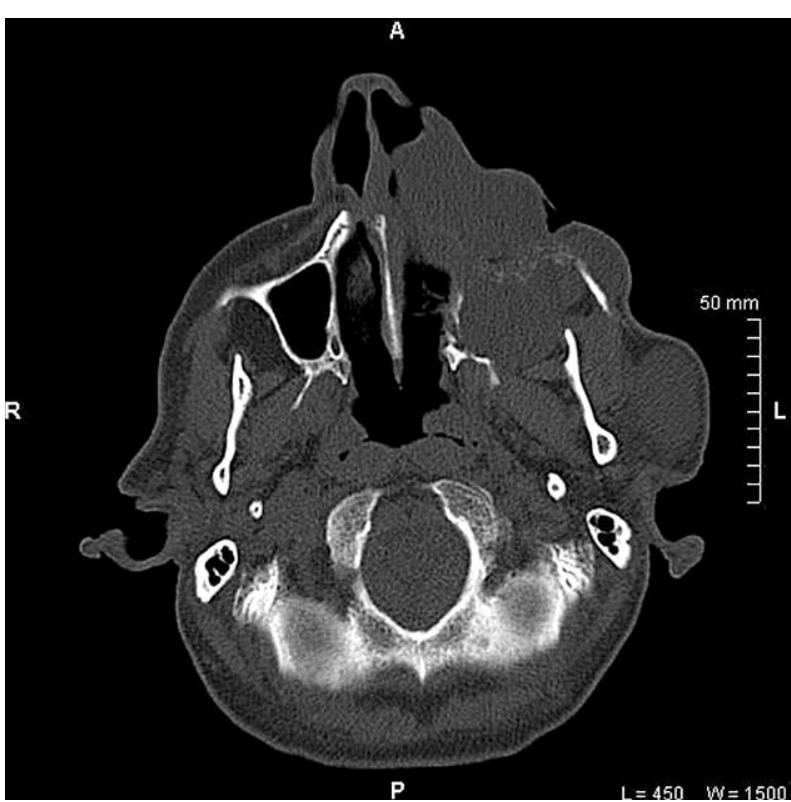

Fig. 3. The same patient - CT scan showing extension of the tumour (horizontal view)

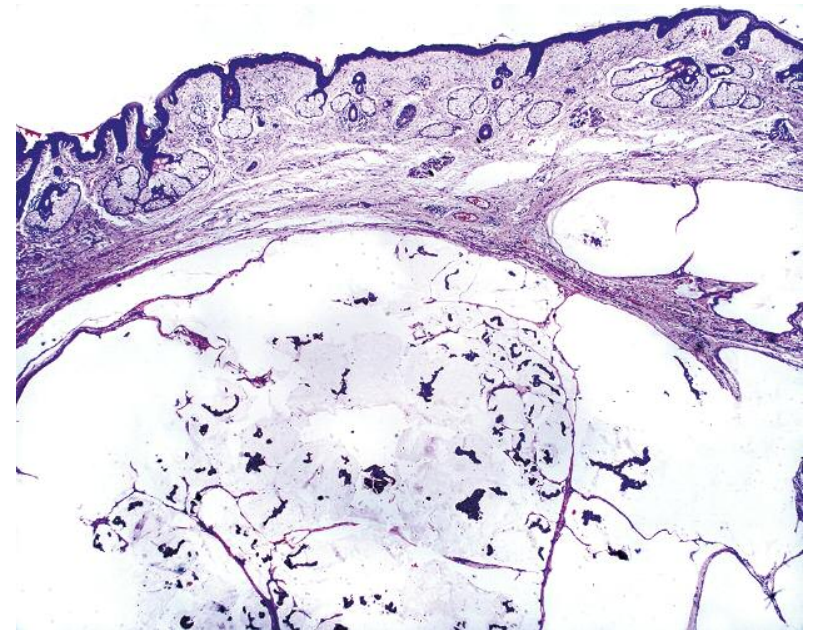

Fig. 5. MAC nests within dermis. HE staining, magnification $25 x$

$\mathrm{X}$-ray image of the chest revealed no distant metastases. The histological result of the biopsy of the tumour of the left cheek revealed recurrent mucinous adenocarcinoma G1 with cancer cells of medium size, with a slightly basophilic cytoplasm and oval nuclei. The cancer cells were arranged in small concentrations and patches embedded in mucus, divided into small cavities (Fig. 5, 6). The cells presented the following pattern of IHC reactivity: CK: AE1/AE3, CK19 positive reactions in the cancer cells; in contrast, $\mathrm{CK} 5 / 6$, CK5/6/18, and SMA were negative. Histochemical reactions - PAS, Alcian blue, mucicarmine - were positive in the cancer stroma (Fig. 7, 8). The tumour originated from a small salivary gland. Due to the severity and advancement of the disease the patient was dis-

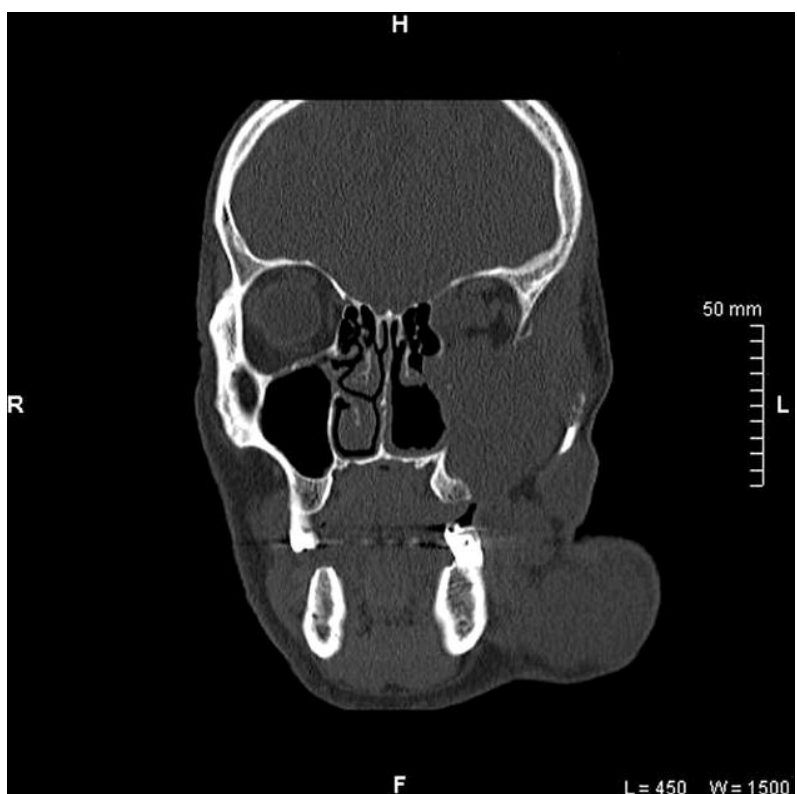

Fig. 4. The same patient - CT scan showing extension of the tumour (frontal view)

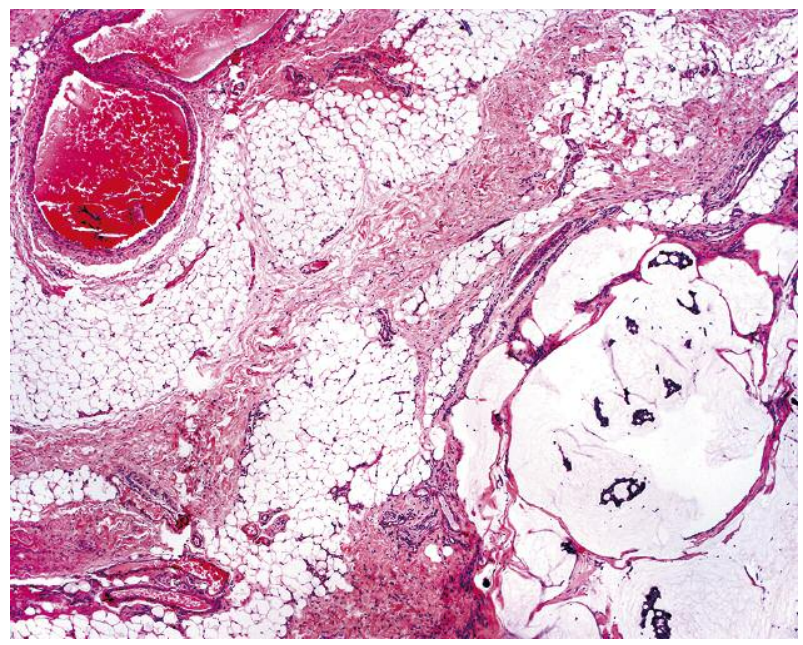

Fig. 6. MAC cells in deep subcutaneous fat tissue. HE staining, magnification $50 \times$

qualified from surgical treatment, reconsulted in the Department of Oncology and qualified for palliative chemotherapy.

\section{Discussion}

As a rare tumour, MAC causes difficulties in diagnosis $[3,5,6,8]$. Clinical symptoms of the head and neck MAC are uncharacteristic and diagnosis is based on the histopathological and immunohistochemical examination. In the available literature (PubMed 19732012) we have found 21 published cases of MAC arising from minor salivary glands localised in the palate (9 cases), buccal mucosa (4 cases), floor of the mouth ( 3 cases), lips ( 3 cases) and tongue ( 2 cases) $[3,6,7,9]$. 


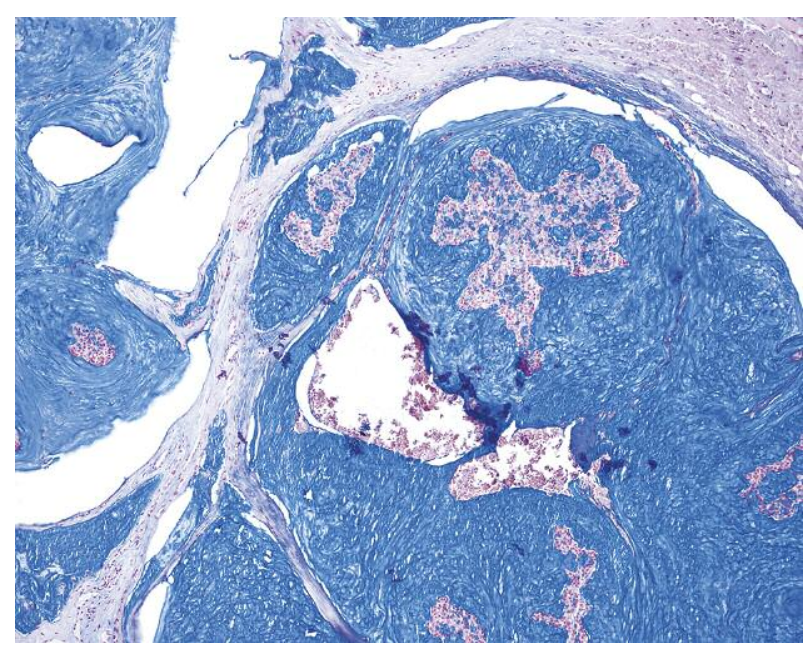

Fig. 7. MAC cells embedded in mucus - in Alcian blue staining, magnification $50 \times$

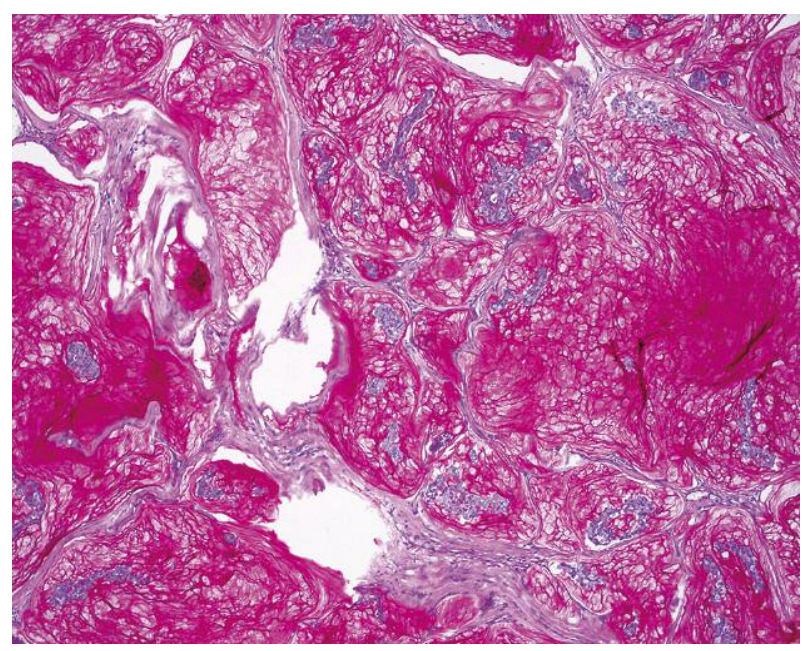

Fig. 8. PAS staining (mucus in pink, cell structures of the cancer in blue), magnification $100 \times$

Table I. Reported cases of MAC arising from minor salivary glands

\begin{tabular}{|c|c|c|c|c|c|c|c|}
\hline REFERENCES & $\begin{array}{l}\text { LOCAL } \\
\text { APPEARANCE }\end{array}$ & AGE & SEX & LOCALISATION & $\begin{array}{l}\text { CERVICAL } \\
\text { LYMPH NODE } \\
\text { METASTASIS }\end{array}$ & TrEATMENT & FOLLOW-UP \\
\hline Shumway & greyish tumour & 72 & male & palate & no & $\begin{array}{l}\text { excision }+ \\
\text { RT }\end{array}$ & 8 months \\
\hline Notani & ulcerated tumour & 64 & male & palate & yes & $\begin{array}{l}\mathrm{RT}+ \\
\text { maxillectomy }+ \\
\mathrm{ND}\end{array}$ & 6 months \\
\hline Gao & ulcerated tumour & 50 & male & palate & yes & not mentioned & not mentioned \\
\hline Gao & ulcerated tumour & 51 & male & palate & yes & not mentioned & not mentioned \\
\hline Gao & exophytic tumour & 58 & female & palate & no & not mentioned & not mentioned \\
\hline Gao & ulcerated tumour & 48 & female & palate & yes & not mentioned & not mentioned \\
\hline Gao & tumour & 70 & male & $\begin{array}{l}\text { floor of } \\
\text { the mouth }\end{array}$ & $\begin{array}{c}\text { not } \\
\text { mentioned }\end{array}$ & not mentioned & 10 months \\
\hline Mano & ulcerated tumour & 70 & male & palate & yes & $\begin{array}{l}\text { excision }+\mathrm{ND}+ \\
\text { chemotherapy }\end{array}$ & $\begin{array}{l}\text { cervical lymph } \\
\text { node metastasis } \\
\text { after } 9 \text { months, } \\
\text { cervical skin me- } \\
\text { tastasis after } \\
20 \text { months }\end{array}$ \\
\hline Seoane & $\begin{array}{l}\text { exophytic fibroma- } \\
\text { like tumour }\end{array}$ & 47 & male & palate & no & excision & not mentioned \\
\hline Aydin & tumour & 80 & male & lip & $\begin{array}{c}\text { not } \\
\text { mentioned }\end{array}$ & excision & 6 months \\
\hline Uchida & tumour & 65 & male & $\begin{array}{l}\text { ventral part } \\
\text { of the tongue }\end{array}$ & no & glossectomy & 6 years \\
\hline Ide & tumour $1 \mathrm{~cm}$ & 76 & female & lower lip & no & excision & $\begin{array}{l}\text { distant metastasis } \\
\text { after } 6 \text { years }\end{array}$ \\
\hline Ide & tumour $1.4 \mathrm{~cm}$ & 82 & female & upper lip & no & excision & $\begin{array}{l}\text { local and nodal } \\
\text { recurrence after } \\
3 \text { years }\end{array}$ \\
\hline Barbosa & tumour & 52 & male & $\begin{array}{l}\text { floor of } \\
\text { the mouth }\end{array}$ & no & $\begin{array}{l}\text { RTGTH + } \\
\text { excision + ND }\end{array}$ & 11 months \\
\hline $\begin{array}{l}\text { Current } \\
\text { case }\end{array}$ & $\begin{array}{l}\text { primarily } \\
\text { tumour } \\
\text { of the cheek }\end{array}$ & $\begin{array}{l}67 \\
(43)\end{array}$ & male & cheek & yes & $\begin{array}{l}\text { multiple } \\
\text { excision }\end{array}$ & 24 years \\
\hline
\end{tabular}

$R T$ - radiotherapy, $N P$ - neck dissection 
The data of 13 patients (reported in English-language literature only) are presented in Table I. In the oral cavity MAC appears as an exophytic, painless tumour of various morphology which clinically may imitate adenoma, fibroma or pyogenic granuloma. MAC of the floor of the mouth resembles calculus of the salivary duct. In differential diagnosis all neoplasms with cells producing mucus should be taken into consideration, e.g. mucoepidermoid carcinoma, mucinous cystadenocarcinoma, mucin-rich salivary duct carcinoma and signet-ring cell adenocarcinoma. An analysis of the reported cases of MAC arising from minor salivary glands revealed that the disease was characteristic for older adults (average age 57 years) with male to female ratio $2: 1$. Cervical lymph node involvement at the time of initial diagnosis of MAC was observed in 12 patients (57.1\%).

Major salivary gland MAC was reported in 9 to 14 patients (some cases might be doubled). In 5 cases the primary tumour was localised in the submandibular gland, in 3 to 8 cases in the parotid gland and in 1 in the sublingual gland. The data concerning the frequency of MAC occurrence in minor and major salivary glands are ambiguous and indicate predominance of MAC arising from minor salivary glands $(2: 1)$ [3-8]. Other atypical localisations of MAC include the nasal cavity, paranasal sinuses and one case of a tumour of the mandibular ramus [8].

In the currently reported case, we believe that the tumour arising from the minor salivary gland of the buccal mucosa was initially misdiagnosed as an epidermal cyst. In our patient immunohistochemical staining revealed positive reaction for $\mathrm{CK} A E 1 / \mathrm{AE} 3$ as well as CK19, and negative for CK5/6, CK5/6/18 and SMA. Also positive staining for PAS, Alcian blue and mucicarmine was obtained in mucin stroma of the cancer. These findings correspond with the results presented by other authors $[4,5,7,8]$.

In commonly observed cases of MAC of the digestive organs well-established algorithms of therapy are available. In the treatment of patients in stage I surgery is the method of choice, in stages II and III surgery combined with chemotherapy, whereas in stage IV surgery combined with chemo/radiotherapy is indicated [10-13]. Based on the current literature, we conclude that the best treatment modality in patients with MAC of the head and neck region is surgery, comprising wide excision of the tumour with concomitant neck dissection. Some authors stress the necessity of adjuvant radiotherapy in these patients. As limited clinical data are not sufficient for establishing clear indications for chemotherapy, in patients with head and neck MAC, the decision should be taken after an analysis of each individual case $[3,4,6,7]$.

\section{Conclusions}

In the cases reported so far, the aggressive character of salivary gland MAC is proved by a high rate of cervical lymph node metastases (about 60\%) present at the initial diagnosis of the tumour as well as a high rate of local recurrence. Such features of the tumour as well as its radioresistance suggest that extensive excision combined with neck dissection is the optimal treatment modality in patients with MAC of the head and neck region. We can hypothesize that in the presented patient exceptionally long follow-up might have been related to unique different chromosomal aberrations in the cancer cells. Appropriate immunohistochemical profiling is mandatory for the proper histopathological diagnosis of MAC.

\section{The authors declare no conflict of interests.}

\section{References}

1. Uchida K, Oga A, Mano T, et al. Screening for DNA copy number aberrations in mucinous adenocarcinoma arising from the minor salivary gland: two case reports. Cancer Genet Cytogenet 2010; 203: 324-7.

2. Spiro RH, Koss LG, Hajdu SI, et al. Tumors of minor salivary origin. A clinicopathologic study of 492 cases. Cancer 1973; 31: 117-29.

3. Ide F, Mishima K, Tanaka A, Saito I, et al. Mucinous adenocarcinoma of minor salivary glands: a high-grade malignancy prone to lymph node metastasis. Virchows Arch 2009; 454: 55-60.

4. Osaki T, Hirota J, Ohno A, et al. Mucinous adenocarcinoma of the submandibular gland. Cancer 1990; 66: 1796-801.

5. Krogdahl AS, Schou C. Mucinous adenocarcinoma of the sublingual gland. J Oral Pathol Med 1997; 26: 198-200.

6. Seoane J, Varela-Centelles P, López-Niño J, et al. Gingival mucinous adenocarcinoma of a minor salivary gland. J Periodontol 2010; 81: 626-31.

7. Notani K, Iizuka T, Yamazaki Y, et al. Mucinous adenocarcinoma of probable minor salivary gland origin. Oral Surg Oral Med Oral Pathol Oral Radiol Endod 2002; 94: 738-40.

8. Hashitani S, Sakurai K, Noguchi K, et al. Mucinous adenocarcinoma with neuroendocrine differentiation of the mandibular ramus: report of a case. J Oral Pathol Med 2004; 33: 59-63.

9. Gao Y, Di P, Peng X, et al. Mucinous adenocarcinoma of salivary. Zhonghua Kou Qiang Yi Xue Za Zhi 2002; 37: 356-8.

10. Safaee A, Moghimi-Dehkordi B, Fatemi SR, et al. Characteristics of colorectal mucinous adenocarcinoma in Iran. Asian Pac J Cancer 2010; 11: 1373-5.

11. Komm M, Kronawitter-Fesl M, Kremer M, et al. Primary mucinous adenocarcinoma of the vermiform appendix with high grade microsatellite instability. J Cancer 2011; 2: 302-6.

12. Chung MY, Park YS, Ryu SR, et al. A case of colonic mucinous adenocarcinoma in 19-year-old male patient. Clin Endosc 2012; 45: 103-7.

13. Ionila M, Margaritescu C, Pirici D, et al. Mucinous adenocarcinoma of the colon - a histochemical study. Rom J Morphol Embryol 2011; 52: 783-90

\section{Address for correspondence}

\section{Piotr Koryczan}

Ludwik Rydygier Hospital in Krakow

Zlota Jesien 1

31-826 Krakow, Poland

tel. +48126468836

fax +48126468539

e-mail: piotrskoryczan@gmail.com 